\title{
Özbek Türkçesinde Edilgen Yapıların Görünümü
}

\author{
Yasin Karadeniz ${ }^{\mathrm{a}, \mathrm{b}}$
}

\section{Özet}

Tarihi ve çağdaş Türk lehçelerinde edilgenlik yapısı için - $l$ ve $-n$ ekleri kullanılmaktadır. Dolayısıyla Özbek Türkçesinde de edilgenlik - $l$ ve $-n$ ekleriyle sağlanmaktadır. Ancak tarihî Türk lehçelerinden günümüzdeki çağdaş Türk lehçelerine kadar bu ekler olmadan yani etken görünümde edilgen yapılar da kullanılmıştır. Bu yapılar Türk dilinde herhangi bir gramer anlamı veya kategorisi taşımamakla birlikte bazı durumlarda görülebilmektedir. Dildeki en az çaba kanunu ya da gereksiz ek tekrarlarından kaçınma gibi çeşitli sebeplerle gramer özelliklerinde eksiltmeye gidilebilmektedir. Bazı dilbilim kaynaklarında sıfır morfem olarak adlandırılan eksiz bu kullanım alanı, söz diziminde kullanılmaktadır. Bu tür kullanımlara edilgenlik eki olmayan sıfat fiilli yapılar örnek olabilir. Özbek Türkçesinde de bu kullanım alanının çeşitli örnekleri tespit edilmiştir.

$\mathrm{Bu}$ çalışmada Özbek Türkçesinde edilgen yapıların nasıl kurulduğu belirtilecek, sonrasında edilgen yapıların kullanımı ekli ve eksiz olmak üzere iki kategoride incelenecektir. Ayrıca diğer Türk lehçelerinden çeşitli örneklerle karşılaştırma yapılamaya çalışılacaktır.
Anahtar Kelimeler

Özbek Türkçesi

Edilgenlik

Edilgen yap 1

Sifat fiil

Makale Hakkında

Geliş Tarihi: 07.01.2021

Kabul Tarihi: 15.12.2021

Doi: $10.18026 /$ cbayarsos. 855717

\section{Appearance Of Passive Structures In Uzbek}

\begin{abstract}
The $-l$ and - $n$ suffixes are used for the passivity structure in historical and contemporary Turkic dialects. Therefore, passivity in also Uzbek is provided by $-l$ and $-n$ suffixes. But, passive structures have also been used from historical Turkish dialects to contemporary Turkic dialects without these suffixes, in other words, active appearance. Although these structures do not have any grammatical meaning or category in the Turkish language, they can be seen in some cases. Can be reduced grammatical features for various reasons, such as the law of least effort in the language or avoiding unnecessary suffixes. This area of usage, which is called zero morpheme in some linguistic sources, is used in syntax. Relative clause constructions without passivity suffix can be examples of such uses. Various examples of this area of use have also been identified in Uzbek.

In this study, it will be stated how passive structures are established in Uzbek, and then the use of passive structures will be examined in two categories as attached and without attachment. In addition, comparisons will be made with various examples from other Turkic dialects.
\end{abstract}

Keywords

Uzbek

Passivity

Passive structure

Adjective verb

About Article

Received: 07.01.2021

Accepted: 15.12.2021

Doi: 10.18026/cbayarsos.855717

a İletişim yazar1: ykaradeniz57@gmail.com

b Arş. Gör. Dr., Manisa Celal Bayar Üniversitesi Fen-Edebiyat Fakültesi, Türk Dili ve Edebiyatı Bölümü, ORCID ID: 0000-0002-0604-1271. 


\section{Giriş}

Diller kullanılmaya başlandığı dönemden günümüze kadar ihtiyaçlara göre kendini güncellemiş ve daha karmaşık bir hâle gelmiştir. Dillerin en eski dönemlerinde yani en basit hâllerinin kullanıldığı dönemlerde, daha basit yapıların kullanılmış olması gayet doğaldır (Karabulut, 2010, s. 367). Türk dilinin bilinen ilk yazılı metinlerinde edilgen biçimbirimlerin/eklerin kullanımının az olması, dilin basit hâli ile açıklanabilir. Ancak Türk dilinin gelişimiyle birlikte edilgen biçimbirimlerin kullanım sıklığın artmasına rağmen biçimbirimsiz yani etken görünümdeki edilgen yapıların da kullanılmaya devam edilmesi dilin basit hâliyle açıklanamaz. Özellikle bu örneklerde sıfat fiil eklerinin sıklıkla kullanılıyor olması da dikkat çeken başka bir noktadır.

Edilgen yapılar, esas itibariyle fiillere getirilen edilgen biçimbirimlerle oluşan ve bu yönüyle fiil çatısını ilgilendiren bir konudur. Bu nedenle Türkiye Türkçesi ve/veya Türk dili üzerine yapılan gramer çalışmalarda genellikle fiil çatısı bölümünde değerlendirilen edilgen yapılar bazı çalışmalarda ise yapım ekleri kategorisinde değerlendirilmektedir. Mesela, Zeynep Korkmaz "Çatıları Bakımından Fiiller" başlı̆̆ı altında fiilleri etken ve edilgen çatılı olmak üzere iki ana başlık altında incelemiştir (2003, s. 538). Tahir Nejat Gencan ve Tuncer Gülensoy ise fiillerin özne ve nesneyle oluşturdukları kuruluşlara çatı denilmesini savunmaktadırlar (1978, s. $171 ; 2000$, s. 404).

Muharrem Ergin ise "Fiilden Fiil Yapım Ekleri" başlığı altında edilgenliği ek bazında değerlendirmiş ve cümleye kattığı anlamı ek temelinde değerlendirmiştir (Ergin 1992, s. 202207). Tahsin Banguoğlu ise edilgenliği, fiillerin görünüş biçimleriyle açıklamış ve edilgenliği çatı bakımından değerlendirmiştir (Banguoğlu, 1995, s. 410).

Edilgen yapılar, doğrudan cümlenin özne alıp almamasına bakılarak tespit edilmemektedir. Yani edilgen çatıdaki bir yapı "Memur yetkililerce başka bir göreve gönderildi." örneğinde olduğu gibi özne alabileceği gibi "Doğru söze kızılmaz." örneğindeki gibi öznesiz de kurulabilmektedir. Türk dilinde edilgen çatılar morfolojik yapılar olduğu için fiilin edilgen biçimbirim alıp almadığına bakılarak tespit edilmektedir. Türk dilinde bu yapıların yanı sıra bazı istisnai durumlar da bulunmaktadır. Etken biçimbirimli edilgenlikler bunun en iyi örneğidir.

Türk dilinde edilgen yapıların oluşumu için cümlenin yükleminin edilgen biçimbirimleri alması gerekmektedir. Yani edilgen yapılar etken yapılardan türetilmektedir (Karabulut, 2011, s. 152). Ancak sıfat fiilli yapılarda bu gereklilik ortadan kalkmaktadır. Türk dilinin tespit edilebilen yazılı ilk döneminden günümüze kadar sıfat fiil eki almış yapılarda edilgenliği ifade etmek için edilgen biçimbirimlerin kullanılmasının şart olmadığı görülmektedir. Bir başka açıdan bakıldığında, sıfat fiilli yapıların Türkçeye bazı kullanım alanları açtığı ya da bazı kuralları ihlal etme fırsatı sağladığı söylenebilir. Bunlara bir örnek olarak şu gösterilebilir. Edilgenlik ekleri Türkçede derin yapıdaki gerçek öznenin yüzey yapıya taşınmasına izin vermemektedir (Üstünova, 2007, s. 744). Bu nedenle edilgen çatıda gerçek özne cümlede yer almamakta, işten etkilenen nesne sözde özne konumuyla öznenin yerini almaktadır (Banguoğlu, 2008, s. 526; Korkmaz, 2017, s. 139). İşte sıfat fiilli yapılar, Türk dilinde derin yapıdaki öznenin yüzey yapıya taşınması imkânını vermektedir. Ayrıca derin yapıda öznenin yaptığı işin yüzey yapıda edilgen olabilmesini sağlamakta ve bu dönüşüm yaşanırken edilgen biçimbirimlerin kullanılmasına gerek duyulmamaktadır. Bu kullanımın örnekleri Köktürk kitabelerinden günümüzdeki çağdaş Türk lehçelerine kadar görülmektedir. Ancak burada tarihî ve çağdaş Türk lehçeleri arasında karşılaştırmalı bir çalışma yapılmayacaktır. Anlatılan 
konunun daha iyi anlaşılması ve bütünsel yaklaşımı göstermesi için, Türk dilinin tarihî seyri içerisinde kullanım biçimlerine göre edilgen yapıların örnekleri verilecek ve Özbek Türkçesindeki kullanım biçimleri gösterilmeye çalışılacaktır.

Ancak edilgen çatıların yani edilgen biçimbirimli fiillerin az kullanılması, edilgen yapıların kullanılmadığı ya da az tercih edildiği sonucunu çıkarmamızı sağlamaz. Çünkü Köktürk Kitabelerinde etken morfolojide edilgenliklerin yani etken biçimbirimli edilgen yapıların kullanıldığı bilinmektedir. Bu kullanımlar Köktürkçeden günümüzdeki çağdaş Türk lehçelerine kadar varlığını sürdürmüştür ve sürdürmeye de devam etmektedir. Bu çalışmada da Özbek Türkçesinde edilgen yapıların nasıl kullanıldığı tartışlacak, Türk dilinin tarihî seyri içerisinde nasıl kullanımların olduğu ve Özbek Türkçesinde bu kullanımların ne şekilde devam ettiği gösterilmeye çalışılacaktır.

\section{Edilgen Morfolojili Yapılar}

\section{a. Edilgen Biçimbirimli Yapılar}

Türk dilinin eski kaynaklarında edilgenleştirici biçimbirim olarak $-l,-n$ yapım ekleri kullanılmıştır. Ancak o dönemin metinleri incelendiğinde edilgen biçimbirimler yardımıyla oluşturuşmuş edilgen çatılı fiillerin kullanım sıklığının az olduğu görülmektedir. Bu açıdan bakıldığında Türk dilinde edilgen biçimbirimlerin tam olarak gelişmediği söylenebilir (Gabain, 1988, s. 59). Bu görüşü Türk dilinde edilgen çatların tarihî gelişimini inceleyen Mevlüt Erdem, Türk dilinin eski dönemlerinde etken çatıların daha yoğun olduğunu ancak edilgen yapıların daha az olduğu tespitiyle desteklemektedir (Erdem, 2007, s. 199-210). Eski Türkçe döneminde edilgen biçimbirimlerin az kullanılmasının yanı sıra etken biçimbirimli edilgen ifadelerin varlığı, edilgen biçimbirimlerin Türk dilinde kullanımının çok da eski olmadığının bir göstergesi olabilir. Etken biçimbirimli edilgen ifadeler sonraki bölümlerde daha ayrıntılı anlatılacağı için burada daha fazla bilgi verilmeyecektir. Türk dilinin sonraki dönemlerinde edilgen yapıların gelişimiyle birlikte, edilgen biçimbirimli fiillerin kullanım sıklığı ve oranı artmıştır. Türklerin hâkimiyet kurduğu alanların ve ilişki kurduğu devletlerin artmasıyla birlikte Türk dilin gelişim seyri ve kullanım biçimleri yeni bir boyut kazanmıştır. Yeni milletlerle ilişkiler ister istemez o devletlerin dilinin Türk dilini etkilemesine neden olmuş, Türk dilinde yeni kullanım biçimleri ve yeni adlandırmalar kullanılmaya başlanmıştır. Mesela Türk dilinin en önemli sözlük ve gramer hazinesi olan Dîvânu Lugati't-Türk adlı eserinde Kâşgarlı Mahmud, edilgen çatılı yapılar için Arapça bir ifade olan "meçhullük" kavramını kullanmıştır. Aynı zamanda Kâşgarlı Mahmud eserinde etken çatıdaki fiillerin edilgenlik ekleriyle edilgen çatıya dönüştürüldüğünü bazı örneklerle açıklama yoluna gitmiş̧tir: bitik bitildi "kitap yazıldı" (DLT, 266), tawar satıldı "mal satıdı" (DLT, 267), er tokındı "adam dövüldü" (DLT, 275) teri telindi "deri yırtıldı" (DLT, 341) böz tokuldı "bez dokundu" (DLT, 269). Tarihî Türk lehçelerinde ve diğer çağdaş Türk lehçelerinde olduğu gibi Özbek Türkçesinde de fiillerin edilgen biçimi, etken çatıdaki fiile eklenen $-l,-n$ ekleriyle oluşturulmaktadır.

Özbek Türkçesi gramer kitaplarında edilgenlik ve edilgen fiiller "majhul, majhul fe'l, majhul nisbat, majhul nisbatdagi fe'l" şeklinde ifade edilmektedir (Gürsoy-Naskali, 1997, s. 37; Hamroyev, 2008, s. 66; To'xliyev vd. 2006, s. 123; Yıldırım, 2012, s. 146; Öztürk, 2005, s. 30-31). Bu türdeki fiillerde özne kullanılmadığ

Mukofot ber-i-1-di. (To’xliyev vd. 2006, s. 123). “Mükâfat verildi.” 
Kitob o'qi-1-di (Hamroyev, 2008, s. 66). "Kitap okundu."

Tog' daryosiday shovillab o'tayotgani bil-i-n-di. (Erk, 15). "Dağ nehri gibi aktığı biliniyordu." Yukarıda örnek cümlelerde fiillerin edilgen biçimbirimleri koyu renkte gösterilmiştir. Bu cümlelerde görüldüğü gibi Özbek Türkçesinde fiillerin edilgen şekillerinin oluşumunda -(i)l, -(i)n ekleri kullanılmaktadır. Bu açıdan bakıldığında Özbek Türkçesinde de Türk dilinin genel kuralları işletilmektedir. Konu çatı açısından incelendiğinde, etken çatılı cümle, edilgen çatılı hâle dönüştürüldüğünde özne geri plana itilmekte ya da cümleden eksiltilerek nesne ön plana getirilmektedir. Özbek Türkçesinde edilgen çatıya dönüştürülen fiillerin geçişli ya da geçişsiz olmasının önünde bir engel yoktur. Yani geçişli fiiller edilgen yapılabilirken geçişsiz fiiller de edilgen çatıdaki yeni yapılar oluşturabilmektedir. Konuyu Türkiye Türkçesinden bir örnek ile gösterecek olursak;

Derste bütün soruları cevap-la-dik.

Şeklindeki etken-geçişli cümle edilgen yapılmak istendiğinde özne düşürülmekte ve fiil edilgen biçimbirime dönüştürülerek fiildeki iş, hareket, eylemin kim tarafından yapıldığ 1 belirsiz hâle getirilmektedir.

Derste bütün sorular cevap-la-n-d1.

Bu biçimdeki yapılarda gerçek özne yoktur. Nesne, sözde özne konumunda kullanılmaktadır. Türk dilinde genelinde olduğu gibi Özbek Türkçesinde de edilgen yapılar bu şekilde yapılmaktadır. Ancak Özbek Türkçesinde bu biçimbirimler kullanılmadan da fiillerin edilgen biçimleri ifade edilebilmektedir. Bu kullanım biçimleri özellikle sıfat fiilli yapılarda karşımıza çıkmaktadır.

Ichkaridan hazin kuy eshit-i-1-di. (To'xliyev vd. 2006, s. 112) "İçeriden hüzünlü bir melodi duyuldu."

Buradaki örnek cümlede eshit- fiilinin edilgen biçimbirimi almasıyla birlikte cümlenin en önemli iki unsurundan birisi olan öznenin eksikliği giderilmek için derin yapıda nesne konumundaki "hazin kuy" yüzeyde sözde özne görevine getirilmiştir. Yine aynı şekilde aşağıdaki cümlelerde derin yapının nesnesi yüzeyde fiilin edilgen çatıya dönmesiyle birlikte özne görevini üstlenmiştir.

O'quvchilarga jadval chizilgan qog'ozlar ber-i-l-adi (Kambarova, 2015, s. 19) "Öğrencilere tablo çizilmiş kâğıtlar verilecek."

Qurultoyda turkiy xalqlarning yozuvlarini lotinlash-tir-il-gan alifbolarga ko'cirish taklifi ma'qulla-n-adi. (Jamolxonov, 2005, s. 120). "Kurultayda Türk halklarının yazılarını latinleştirilmiş alfabelere çevirme teklifi kabul edilecek."

\section{b. Edilgen Yapılarda Sıfat Fiil Ekinin Kullanımı}

Etken çatılı fiillere $-l$ ve $-n$ eklerinin getirilmesiyle oluşan edilgen yapılar, Türk dilinin tarihî seyri içinde günümüze kadar kullanılagelmiştir. Günümüzde diğer çağdaş Türk lehçelerinde olduğu gibi Özbek Türkçesinde de aynı edilgen biçimbirimlerle edilgen yapılar oluşturulmaktadır. Özbek Türkçesinin edilgenlik ekleri olan $-l v e-n$, Türk dilinin tarihî seyri içerisinde Eski Uygur Türkçesinden Çağatay Türkçesine kadar kullanım alanını artırarak gelmiş ve günümüzde de çağdaş Türk lehçelerinde de genel olarak kullanılmaktadır (Duru, 2008, s. 97-125). 
Ancak sıfat fiil ekleriyle birlikte edilgen çatılı fiillerin oluşturdukları yapılar, Türk dilinin yazılı ilk örneklerinde kullanılmamış ya da çok nadir kullanılmıştır (Duru, 2008, s. 91; Karabulut, 2011, s. 141). Karahanlı Türkçesi dönemine gelindiğinde sıfat fiil ekleriyle birlikte edilgen çatıdaki fiillerin oluşturduğu yapılar daha sık kullanılmıştır. Çağatay Türkçesinin mirasının büyük bir bölümünü günümüzde kullanmaya devam eden Özbek Türkçesinde de edilgen yapılarda sıfat fiil ekleri çok sık kullanılmaktadır. Günümüzde çağdaş Türk lehçelerinde kullanım alanı bakamından işlek olan -gan sıfat fiil eki, Özbek Türkçesinde edilgen yapıların oluşumunda da aktif bir şekilde kullanılmaktadır.

Özbek Türkçesinde edilgen çatılı yapılar etken çatıdaki fiillere sadece edilgen biçimbirimlerin getirilmesiyle yapıldığı gibi sıfat fiil ekiyle birlikte kalıplaşan edilgen biçimbirimli yapılar da kullanılmaktadır. Özellikle bu yapılar birleşik cümlelerde karşımıza çıkmaktadır. Bu kullanım biçimlerini daha iyi ifade edebilmek için edilgen biçimbirimlerin semantiği kadar sıfat fiil ekleriyle birlikte kurulan birleşik cümle yapılarının incelenmesi gerekmektedir. Bunun için de cümlelerin derin ve yüzey yapıdaki kullanımlarını incelenmelidir.

Mahorat bilan yarat-i-l-gan iyhom kishini hayratga soladi (Kambarova, 2015, s. 27) “Ustalıkla yaratılan evham insanı şaşırtır."

Buradaki örnek cümle, tek bir yargı ifade ediyormuş gibi görünse de aslında derinde iki farklı yargının yani iki cümlenin yüzeyde sıfat fiil ekinin yardımıyla birleşmiş ve yüzeyde hayratga sol- fiilinin ana cümlenin yüklemi görevini üstlenmiş halinden ibarettir. Konumuzu daha iyi anlatabilmek adına yüzey yapıda birleşmiş cümlenin öncelikle derindeki görünümlerini ortaya koymaliyız.

1a) (U) iyhomni mahorat bilan yaratti.

1b) Iyhom mahorat bilan yaratilgan.

2) Iyhom kishini hayratga soladi.

Özbek Türkçesinde edilgen çatıdaki fiiller, etken fiillere edilgen biçimbirimlerin getirilmesiyle oluşmaktadır. Bu nedenle birleşik cümlenin derindeki görünümlerini ifade edebilmek adına öncelikle derin yapıdaki cümlenin daha önceki hâli yani 1a örneğinde görüldüğü gibi önceki derin yapısı olan etken hâlini, sonrasında ise $1 b$ örneğindeki edilgen şeklini vermek daha doğru olacaktır. Cümlelere daha yakından bakılacak olursa 1a örneğindeki etken çatılı fiile $-l$ edilgen biçimbirimini eklemek için özne düşürülmüş ve derin yapıdaki nesne yüzeyde özne konumuna getirilmiştir. Sonrasında $1 b$ cümlesi sıfat fiil ekinin yardımıyla yüzeydeki en son hâlini alarak birleşik cümlenin yan cümlesini oluşturmuştur. Sıfat fiil ekiyle oluşan yan cümle edilgen iken yüzeydeki ana/temel cümlenin fiili etken olabileceği gibi birleşik cümlenin hem yardımc fiili hem de ana fiili edilgen olabilir.

Otabek kut-i-1-magan bu savoldan ajablandi (Qodiriy, 2016, s. 12). “Atabek beklenmedik bu soru karşısında şaşırdı."

Otasi qama-1-gan kuni aytgan so‘zlari... (Yoqubov, 2005, s. 79) “Babasının tutuklandığı gün söylediği sözleri..."

Bu forma ba'zan nutq momentidan ilgari bajar-i-l-gan harakati bildiradi. (Tursunov vd., 1975, s. 202). "Bu biçim bazen konuşma anından önce gerçekleştirilen bir eylemi ifade eder."

Uning gaplaridan ko'ngli ko'tar-i-l-gan Abdurahmonov domla "Onun sözlerinden rahatsız olan Abdurahman damla." 
Xususan ber-i-l-gan holat ravishlari. "Özellikle verilen durum zarfları"

O'quv mashg'ulotlariga ajrat-i-l-gan vaqtning asosiy qismini amaliy ishlar egallashi lozim. (Tơxliyev vd. 2006, s. 116) “Ders çalışmaları için ayrılan sürenin esas kısmını pratik işlere ayırması lazım."

Biz kónlingda yoz-i-1-ganlarni barala o'qib turibmiz (KK, 153). “Biz gönlünde yazılanları apaçık okuyoruz."

Ber-i-l-gan fe'llarning qaysi nisbatga qarashli ekanligini toping (Tóxliyev vd. 2006, s. 123). "Verilen fiillerin hangi çatıya bağlı olduğunu bulun."

Buradaki örnek cümlelerden görüleceği gibi Özbek Türkçesinde edilgen biçimbirimlerle daha çok "-gan" sıfat fiil eki kalıplaşarak birleşik yapılar oluşturmaktadır. Bunda -gan sıfat fiil ekinin Özbek Türkçesinde kullanım alanının genişlemesi ve en yoğun kullanılan sıfat fiil eki olması etkili olmuştur (Karadeniz, 2019, s. 89-106). Birleşik yapılarda her iki yargı da edilgen biçimbirim alabildiği gibi sadece yardımcı cümlenin fiili de biçimbirim almaktadır.

\section{c. Edilgen Yapılarda Eskicil Unsurlar}

Türk dilinin ilk yazılı metinlerinden olan Orhun Yazıtlarında cümle kurgusu daha çok etken çatıdadır. Bunun yanı sıra dünya dillerinin ilk yazılı metinleri üzerinde çalışmalar yapan dilbilimciler de özne ve yüklemin eski metinlerde en önemli iki unsur olduğunu vurgulamaktadır. Günümüzde Afrika, Amerika ve Avustralya'da yaşayan kabilelerin dillerine bakıldığında da etken çatılı yapıların daha ön planda olduğu görülmektedir (Pinker, 1995). Konuya Türk dili bağlamında bakıldığında Orhun Yazıtlarında etken çatılı cümlelerin daha sık kullanılması, yazılış amacıyla yani bir hitabet örneği olmasıyla açıklanabilir. Ancak dünya dillerinin tarihiyle birlikte düşünüldüğünde dillerin etken çatı üzerine oluşması ve edilgen çatılı kullanımların dilin sonraki dönemdeki gelişmesiyle de açıklanabilir. Bu açıdan Türk dilinin ilk yazılı örneklerinde edilgen biçimdeki yapıların az kullanılmış olması dilin tarihî seyri içindeki gelişimiyle ilgili olabilir.

Türk dilinin tarihî seyri içinde edilgen yapıların oluşumu incelendiğinde bazı son çekim edatlarının (özellikle tarafından edatı) ya da hâl eklerinin edilgen yapıların belirginleşmesinde önemli bir rolü üstlendiği görülmektedir. Türk dilinin tarihî dönemlerinden itibaren bazı hâl ekleri, özellikle yönelme, ayrılma ve eşitlik hâli ekleri, edilgen yapılarda aktif rol almaktadır. $\mathrm{Bu}$ durum, günümüzde çağdaş Türk lehçelerinin büyük bir bölümünde görülmektedir. Mesela Sibirya (Kuzey-Doğu) grubu Türk lehçelerinde yönelme hâl eki, özneyi belirginleştirmede kullanılan önemli bir ektir (Baasanjav, 2006, s. 237).

Andreev ismindag'i Skobel maorif rahbari tomonidan majburiy yop-i-1-di. "Andreyev ismindeki Skobel eğitim başkanı tarafından zorla kapatıldı."

$\mathrm{O}^{\prime}$ zim 4 oycha davom ettirgandan keyin, uyaz nachalnigi (Medinskiy) tomonidan tintuv bo'lub, yop-i-l-di. "Ben 4 ay boyunca devam ettirdikten sonra Medinskiy tarafından aranıp kapatıld1."

Samarqanddagi soldatlar tomonidan ozod qil-i-n-ishi kabi voqealar aks etgan. (F1trat, 1993)

"Semerkant'taki askerler tarafından serbest bırakıldığına dair raporlar varmışı."

Görüldüğü gibi buradaki örneklerde "tomonidan" son çekim edatı ile cümledeki edilgen yapılar öbek yapı oluşturmuş ve edilgenlik ifadesi daha belirgin hâle gelmiştir.

Hâl ekini almış nesnenin özne konumuna yükseltildiği edilgen yapılar, tarihî metinlerden çağdaş Türk lehçelerine miras kalan bir kullanım örneğidir. Özbek Türkçesi metinlerinde de 
bu tipteki kullanımlar çok sık olmamakla birlikte varlığını sürdürmektedir. Özbek Türkçesinde bazı örneklerde ise hâl ekiyle birlikte çekimlenen edilgen yapılarda hâl eki vasıtasıyla, sebebiyle, olarak anlamını katmaktadır. Aşağıdaki cümlelerde bulunma ya da ayrılma hâli eliyle birlikte çekimlenen edilgen yapılar cümleye vasıtasıyla, sebebiyle, olarak anlamlarını katmıştır:

Mirzo Ulug'bek uyqusizlik-dan qisilgan ko'zlari yonib, o'g'li Abdul'aziga qaradi (UX, 78). "Mirza Uluğbey uykusuzluktan yanan gözlerini kısarak Abdulaziz'e baktı."

Elbek lirik shoir sifati-da ham tani-1-gan edi (Elbek, 1999, s. 10) “Elbek aynı zamanda lirik şair olarak biliniyordu."

Marmar bo'laklarini asosiy massadan ajratib olish qo'1-da bajar-il-adi. “Mermer parçalarının ana kütleden ayrılması işi elle yapılacak."

Buradaki örnek cümlede ayrılma hâli ekiyle birlikte edilgen yapılar cümleye hammadde, kaynak vasıtasıyla anlamlarını katmıştır.

Oltin-dan to'q-ul-g'on tor bir qafasda (Elbek, 1999, s. 23) "Altından yapılmış küçük bir kafeste."

Boshlarida echki terisi-dan tik-il-gan uchlik kuloh, qo'llarida isiriq tut-il-gan kachkul... (UX, 34) "Başlarında keçi derisinden dikilmiş üçlü şapka, ellerinde tütsülenmiş bir keşkül..."

Ilm ishining turkchasi-dan undir-il-gan so‘zlar shulardir. (Fitrat, 1993) “Türkçe bilim dilinden alınan kelimeler bunlardır."

\section{ç. Edilgen Yapılarda Çatı Nöbetleşmesi: Dönüşlülük}

Türk dilinde genel olarak edilgen çatı ile dönüşlü çatıdaki fiiller aynı biçimbirimlerle $(-l,-n)$ türetildiği için zaman zaman edilgen ve dönüşlü çatıdaki yapılar birbirine karıştırılmaktadır. Oysa dönüşlü çatıdaki yapılarda eylemi gerçekleştiren özne, doğrudan yaptığı işten etkilenmektedir. Yani eylemin etkisi bir şekilde özneye geri dönmektedir. Türk dilinde edilgen çatı ile dönüşlü çatıdaki yapıları kesin olarak birbirinden ayırabilecek morfolojik bir kuruluş yoktur. Bu nedenle burada semantik konusu devreye girmektedir. Dolayısıyla, morfolojik olarak aynı biçimbirimlerle kurulmuş edilgen ya da dönüşlü yapıları ayırmak için kurulan cümlelerin anlam boyutuna bakılmalı, fiil-özne ilişkisi gözden geçirilmelidir. Dönüşlü çatıdaki yapılarda gerçek öznenin yaptığı iş, kendisine dönmektedir. Bu yapıları bir örnek cümle üzerinden anlatmaya çalışalım;

Ali yıkandı.

Bu cümlede gerçek özne konumundaki “Ali”, hem derin hem de yüzey yapıda aynı konumda ise

Ali birisi tarafindan yıkandı.

şeklinde bir anlam ifade etmesi düşünülemez. Çünkü derin yapıdaki özne yüzey yapıda da özne konumundadır ve herhangi bir boşluk olmadığ 1 için ikinci örnekteki ifade yanlıştır. Derin yapıdaki bir cümlenin yüzeyde herhangi bir anlam değişimi olmadığını anlamak için yapıların diğer cümlelerle semantik bağlantısı incelenmelidir. Birinci örnekteki cümle tek başına düşünüldüğünde özne eylemi kendisi mi yaptı yoksa derin yapıdaki nesne boşluğu doldurmak için özne konumuna mı yükseltildi net değildir. Bunu kesinleştirmek için yapı semantik açıdan da incelemeye alınmalıdır. 


\section{Elma yikandi.}

Buradaki örnekte ise derin yapıdaki nesne iken yüzey yapıda özne konumuna yükselmiş bir yapı vardir.

Bu yapılardaki cümlelerde özne, nesne görevini de yürütmektedir. Türk dili üzerine araştırma yapan hemen hemen herkesin dönüşlü çatıyla ilgili görüşü, yapılan işin özneye geri dönmesi noktasında ortaktır. Mesela Zeynep Korkmaz dönüşlü çatıları “işin kendin kendine yapıldığı ya da öznenin yaptığı işin kendine dönmesi” şeklinde açıklamıştır (2003, s. 550). Dönüşlü çatıdaki yapılar tarihî Türk lehçelerinden günümüzde çağdaş Türk lehçelerine kadar kullanılagelmiştir. Günümüzde diğer Türk lehçelerinde olduğu gibi Özbek Türkçesinde de kullanımını sürdürmektedir. Dönüşlü çatılar Özbek Türkçesinde "o'zlik nisbati" şeklinde ifade edilen çatıdaki fiillerdir. Bu fiiller iş-hareketin sahibine döndüğünü ifade etmektedir: bezandi "süslendi", quvondi "sevindi", berildi "verildi", sudroldi "sürüklendi" (To'xliyev vd. 2006, s. 123). Özbek Türkçesinde meçhul ve dönüşlü çatıdaki fiiller aynı eklerle yapılır. İki yapıyı birbirinden ayırabilmek için semantik konusu devreye girmektedir. Kullanıldıkları cümlenin anlamına göre fiillerin dönüşlülük ya da meçhullük ifade ettiğini anlayabiliriz. Aşağıdaki örneklerde her iki cümlenin öznesi de yaptıkları işten doğrudan etkilenmekte, eylemin etkisi özneye geri dönmektedir. Dolayısıyla dönüşlü çatıdaki yapıya örnek teşkil etmektedir. U nihoyatda sipo va ozoda kiy-i-ng-an edi. "O son derece mütevazi ve temiz giyinmişti." Falonchi yozuvchi falon yili falon shaharda tug'-i-1-di... "Falanca yazar, falanca yıl falan şehirde doğdu..."

\section{Biçimbirimsiz Edilgen İfadeler}

Türk dilinde edilgen yapıların nasıl kullanıldığına bakılırsa, art zamanlı ve eş zamanlı dilbilimi incelemelerinde olduğu gibi Türk dilinin temelini etkenliğin oluşturduğu görülmektedir. Özellikle yargı bildiren cümlelerin en temel iki unsur üzere kurulduğu görülmektedir. Bunlar bir eylem, hareket, iş ve bu eylemi, hareketi, işi yapan özneden oluşmaktadır. Özne cümlede doğrudan yer alabileceği gibi gizli özne şeklinde de kullanılabilir. Türk dilinin ilk yazılı belgeleri kabul edilen Köktürk Kitabelerinde kurulmuş cümleler incelendiğinde etken çatılı kullanımların çoğunlukta olduğu görülmektedir. Kitabelerin bu yapısının birinci ağızdan bir hitabet ürünü olmasıyla ya da Türk dilinde edilgen çatılı yapıların sonraki dönemlerde kullanıma girmiş olmasıyla açıklanabilir. Dünya dilleri üzerine araştırmalar yapan ve Türk dilinin tarihî gelişimi üzerine araştırmalar yapan Türkologların görüşleri de bu doğrultudadır (Kornfilt, 1991, s. 18-20).

Türk dilinde fonem ve morfem olarak kullanılmayan ancak söz diziminde karşılığı olan biçimbirimsiz bir başka deyişle sıfır morfem denilen eksiz gramer kategorileri bulunmaktadır. Mustafa Öner "Nominatif ve Sıfır Morfem" adlı çalışmasında Türk dilinde özellikle yalın hâlde sıfır morfem kullanıldığını belirtmiştir (2013, s. 160-162). Türk dilinde edilgenlik ekleri olarak $-l$ ve $-n$ kullanılmaktadır. Ancak bu ekler kullanılmadan yani sıfır morfem gramer kategorisi içinde değerlendirilebilecek kullanımların tarihî Türk lehçelerinden çağdaş Türk lehçelerine kadar örnekleri bulunmaktadır (Atay, 2019, s. 458). Bu örnekler Türk dilinin tarihî seyrine göre şu şekilde gösterilebilir.

Köktürk kitabelerinden şu şekilde bir örnek verilebilir; 
Ança ḳazġanmış itmiş ilimiz törümüz erti (I D 22, Orkun, 1987, s. 38). “Böyle kazanılmış, tanzim edilmiş ülkemiz, töremiz var idi."

Buradaki örnekte kazğan- ve it- fiilleri biçimbirimsiz edilgenliği ifade edecek şekilde kullanılmıştır.

Eski Uygur Türkçesi döneminde -er, $-\dot{g} u,-u k$ gibi çeşitli sıfat fiil ekleri bazı durumlarda etken görünümde ama anlam olarak edilgenliği ifade eden yapılarda kullanılmıştır: kutgarg்u tınlığları̀g tapduḳda ḳodmatın ḳamaguun ḳutḳartığız (ETŞ 7/ 131-132). "Kurtarılacak mahkûmları bulunca hiçbirini bırakmadan hepsini kurtardınız."

Ḳılmayụ̣ ayı่̀ ḳılınçları̀g ikileyü taḳı ḳılmaz men (Suv. 138/ 3). “Kılınmamış kötü amelleri bir daha tekrar etmem." (Eraslan, 1999, s. 125).

Sever oġuluñ ermez mü men? (Eraslan, 2012, s. 362). "Sevilen oğlun değil miyim?"

Etken görünümdeki edilgen yapıların kullanımına Karahanlı döneminde de devam edildiğini ve bu kullanımların önceki dönemlere göre biraz daha sıklaştığı görülmektedir.

Törütgen barınga törütmiş tanuk

Törümiş iki bir tanuḳı anuḳ (KB 15) "Yaratıcı varlığına yaratılmış olanlar şahittir; yaratılan (türeyen) iki, birin hazır şahididir." (Arat, 1991, s. 13).

$\mathrm{Bu}$ örnekte törü- fiilinin etken yapıda kullanıldığını ve Türkiye Türkçesine aktarıldığında edilgen bir ifadenin ortaya çıtı̆̆ı görülmektedir.

Yine Atabetü'l-Hakayık'ta

Āyā şāhım erdemlerin sanag̉an

sanar mu ediz ḳum uşaḳ taş sanı (AH 59,60) "Ey şahımın erdemlerini sayan kimse sahradaki kum ve ufak taşlar sayılır mı?" (Arat, 2006, s. 84) örneğinde -ar sıfat fiil eki ile edilgenliğin ifade edildiği görülmektedir.

Harezm Türkçesi dönemi eserlerinden Kısasü'l-Enbiya'da $-g A n$ sıfat fiil ekinini biçimbirimsiz edilgenliğin ifade edildiği örnekler mevcuttur.

Yana bażı rivāyetde bu aygan māllarnıñ tėgme biri Yūsufnıñ on ag̉ırınça muḳarrer boldı (KE, 75v-8). "Yine bazı rivayette söylenen malların her biri Yusuf'un on ağırlığınca belirlendi." (Ata, 2019, s. 148).

Bir başka örnekte de aynı şekilde biçimbirimsiz edilgenlik ifade edilmektedir:

Ve līkin Ādemdin burunrak yaratg̉anlar bar üçün andın başlasak fāyidesi artuḳraḳ bolg̀ay (KE. 3r-1,2). (Ata, 2019, s. 37).

Örneklerde görüldügü üzere Türk dilinin yazılı ilk metinlerinden 14. yüzyıldaki Harezm Türkçesine kadar geçen dönemde dönemin özelliklerini yansitan birçok eserde biçimbirimsiz edilgen yapıların kullanılmış olması belirli bir dönemle izah edilemeyeceği gibi bu yapılarda farklı fiillerin kullanılmış olması, biçimbirimsiz edilgen ifadelerin bazı fiillerle sınırlandırılamayacağını da göstermektedir.

15. yüzyıldan 20. yüzyılın başlarına kadar kullanılan Çağatay Türkçesi, tarihî Türk lehçelerinin özelliklerinin çağdaş Türk lehçelerine aktarılmasında önemli bir rol oynamıştır. Çağatay Türkçesinin ana mirasçısı olması hasebiyle, bugünkü Özbek Türkçesinde Çağatay Türkçesinde sıklıkla kullanılmış olan etken biçimbirimli edilgen ifadeler görülebilmektedir. 
Çağatay Türkçesi döneminde $-m I s ̧$ sıfat fiil eki yerini daha çok $-g A n$ ekine bırakmıştır. Çağatay Türkçesi döneminde $-g A n$ sıfat fiil ekiyle etken görünümlü edilgen yapıların daha çok kullanıldığı görülmektedir. Bu konuda Eckmann; fail ismi veya devam eden tamamlanmış fiil hareketini ifade eden $-g A n$ eki, geçişli hem aktif hem de pasif anlama geldiğini söyleyerek bu yapılara dikkat çekmiştir (Eckmann, 2003, s. 100).

Çağatay Türkçesinin uzun bir süre Türkistan coğrafyasının ortak yazı dili olduğu göz önünde bulundurulduğunda diğer çağdaş Türk lehçelerinde de $-g A n$ sıfat fiil ekinin biçimbirimsiz edilgen yapılarda kullanılması açılanabilir. Çünkü az önce de dile getirildiği gibi Çağatay Türkçesi döneminde $-g A n$ sıfat fiil ekinin kullanım alanı genişlemiş $-m I s ̧$ ekinin yerini de almaya başlamıştır. Mesela Kırgız Türkçesinde bu biçimdeki kullanımlar tespit edilmiştir.

Bürkütü tıtıp ketken añçanın katını sensiñbi? (Turgunbayev, 2004, s. 11). “Kartal tarafından tırmalanmış avcının karısı sen misin?"

Aynı şekilde Çuvaş Türkçesinde de edilgen biçimbirimler $-l$ ve $-n$ olduğu hâlde bu biçimbirimler kullanılmadan edilgenliğin ifade edildiği örnekler vardır.

Şiternı̆ ̌̆y̆r Şitmil pit turtň̆.

"Yedirilen aygır yetmiş pud çekmiş."

İr aknĭ vĭrlı̆h saya kaytmas (Yilmaz, 2002, s. 102-103).

“Erken ekilen tohum boşa gitmez."

Çuvaş Türkçesindeki bu örneklerde $-n \breve{\imath}$ geçmiş zamanı ifade eden sıfat fiil ekiyle edilgenlik ifade edilmiştir.

Yine Başkurt Türkçesinde de çeşitli ses değişimine uğramış sıfat fiil ekiyle edilgen biçimbirimsiz kullanım tespit edilmiştir.

Uq1yhı kitap “Okunası kitap."

Kitähř yul "Gidilesi yol.” (Yazıcı Ersoy, 2007s. 793)

Karaçay Türkçesinde de $-g A n$ sıfat fiil ekiyle biçimbirimsiz edilgenliğin ifade edildiği örnekler mevcuttur.

Toyğan cerden tuvğan cer igidi. “Doyulan yerden doğulan yer daha iyidir.”

Aynı şekilde Yeni Uygur Türkçesinde biçimbirimsiz edilgen yapıların kullanımında $-g A n$ sıfat fiil ekinin yanı sıra $-g U$ ve $-G ı S U$ sıfat fiil eklerinin de kullanıldığı görülmektedir.

Körgen çüş. “Görülen rüya."

Térilgu yér. "Ekilecek yer."

Yetkisü menzil “Ulaşılacak menzil.”

Balilik tan peyti körgen çüş kebi

Bek enık ḳalidu insan yadida (Ercilasun, 2005, s. 202).

“Çocukluk tan vakti görülen düş gibi pek açık kalıyor insan zihninde.”

Kıpçak ve Karluk grubu Türk lehçelerinde olduğu gibi Altay Türkçesinde de $-g A n$ ve $-A r$ sıfat fiil eklerinin biçimbirimsiz edilgen yapıların ifade edilmesinde kullanıldığ görülmektedir.

Atqan oqtıy uçup iydi. "Atılan ok gibi uçup gitti.” 
Aytqan sös atqan oq. "Söylenen söz atılan ok gibidir."

Hakas Türkçesinde de $-g A n$ sıfat fiil ekinin bazı ses değişimleriyle -cañ, -han şekilleri biçimbirimsiz edilgenliğin ifadesinde kullanılmaktadır.

Athan uh aylanmacañ. "Atılan ok dönmez."

Bu örnekleri çoğaltabiliriz. Görüldüğü gibi Kıpçak, Karluk ve Altay grubu Türk lehçelerinde Özbek Türkçesinde olduğu gibi bazı sıfat fiil ekleriyle özellikle de $-g A n$ sıfat fiil ekiyle biçimbirimsiz edilgenliğin yani edilgenlik ekleri kullanılmadan sıfır morfem kategorisinde edilgenliğin ifade edildiği görülmektedir. Bunların hepsinin ortak noktası ise sıfat fiil ekinin de kullanılmasıyla birlikte biçimbirimsiz edilgenliğin ortaya çıkmasıdır. Aynı şekilde Oğuz grubu Türk lehçelerinde de bu türde kullanımların olduğu bilinmektedir. Mesela Azerbaycan Türkçesindeki kullanımlar örnek verilebilir.

Sözläär söz. “Söylenecek söz.” (Kara, 2011, s. 130).

Geçdik köpri "geçilmiş köprü" (Buran-Alkaya, 2013, s. 143)

Aynı şekilde Türkmen Türkçesinde de yine sıfat fiil ile edilgenliğin ifade edildiği kullanımlar mevcuttur.

Onuñ Gencim beg, Mömin beg, Adı beg diyen ogulları vardı (Kara, 2011, s. 129).

“Onun Gencim beğ, Mömin beğ, Adı beğ denen oğulları vardı.

Burada diyen kelimesinde de- fiiline eklenen sıfat fiil eki ile "diyen" biçiminde Kıpçak ve Karluk grubu Türk lehçelerinde olduğu gibi “denen, denilen” anlamında kullanılmıştır. Örneklerden tespit edilebildiğine göre Eski Türkçe dönemindeki -gma, -gu sıfat fiil ekinin zayıflamasıyla birlikte ileriki dönemlerde özellikle Kıpçak ve Karluk grubu Türk lehçelerinde $-g A n$ sıfat fiil eki edilgenleştirme özelliğini yürütmeye devam etmiştir. Bunun yanı sıra $-A r$ eki de anlam bakımından edilgenleştirme görevindedir. Batı grubu Türk lehçelerinde ise $-A n$ eki en sık karşılaştığımız edilgenleştirici görevindedir.

Bu örneklerden de görülebildiği gibi tarihî Türk lehçelerinden çağdaş Türk lehçelerine kadar çeşitli değişimler olmakla birlikte biçimbirimsiz edilgenlikler yeri geldikçe etkin bir şekilde kullanılmaktadır. Özbek Türkçesinde de bu yapıların etkin bir şekilde kullanıldı̆̆ı verilen örneklerden hareketle söylenebilir. Peki, Türk dilinde $-l$ ve $-n$ edilgen biçimbirimleri olduğu ve Özbek Türkçesinde de bu ekler kullanıldığı halde neden bazı durumlarda bu biçimbirimler kullanılmadan edilgenliğin ifade edilmesi yolu seçilmiştir? Bu konuyu açıklamadan önce Özbek Türkçesinde biçimbirimsiz ya da sıfır morfem kategorisinde edilgenliğin nasıl ifade edildiğini çeşitli örnekler vasıtasıyla gösterelim.

Borgan yer. "Gidilen yer"

Yozgan kitob "Yazılan/yazılmış kitap"

Aytar söz. "Söylenen söz."

Ko'rgan chush "Görülen rüya"

$\mathrm{Bu}$ örneklerde görüldüğü üzere Özbek Türkçesinde biçimbirimsiz edilgenliğin ifade edilmesinde çeşitli sıfat fiil ekleri özellikle de -gan sıfat fiil eki kullanılmaktadır. Özbek Türkçesinde özne konumundaki ögenin silinmesiyle bu tür kullanımların ortaya çıktığ 
görülmektedir. Özbek Türkçesinde bu türdeki kullanımların sayısı bir hayli fazladır. Özellikle - gan sıfat fiil eki, edilgen biçimbirimsiz yapılarda öne çıkmaktadır.

Birinchi ona tili kursi degan maqola ham chiqqan (Fıtrat, 1993). “Birinci ana dili dersi denilen makale de çıkmış."

Yusupsizlik degan hollar turkcha sarfda sira yo'qdur (Fitrat, 1993). "Kuralsızlık denilen durumlar Türkçe morfolojide asla yoktur."

Yozgan jumlalarini bosh hatdan o'hib, yana bir necha yerini tuzatdi. (Fitrat, 1993). "Yazdığ1/ yazılan cümleleri başlığından itibaren okuyup yine birkaç yerini düzeltti."

Özbek Türkçesinde de- fiili etken yapıda kullanıldı̆̆ı gibi bazı örneklerde biçimbirimsiz edilgenliği de ifade etmektedir. de- fiilinin bu şekildeki kullanımı Özbek Türkçesinin yanı sıra diğer çağdaş Türk lehçelerinde ve tarihî Türk lehçelerinde görülmektedir.

Tursumbetov degan qirg 'izni polkda hamma bilar edi (Qahhor, 1988, s. 14). "Tursumbetov denilen Kırgız'ı alaydaki herkes tanıyordu."

Buradaki örnekte de- fiiliyle birlikte -gan sıfat fiil eki eksiz edilgen yapıda kullanılmıştır. Çalışmamızın başında Türk dilinde biçimbirimsiz yapıların kullanımını ifade ederken bu kullanımların bazı fiillerle sınırlandırılamadığını söylemiştik. Ancak de- fiili örneğinde olduğu gibi çok az örneği olmakla birlikte tarihî Türk lehçelerinden günümüzdeki çağdaş Türk lehçelerine kadar bazı fiillerin biçimbirimsiz edilgenlik ifadesinde daha sık kullanıldığ söylenebilir.

Bola otasi yozgan kitobni olib keldi. “Çocuk, babası tarafından yazılan kitabı getirdi.”

Özbek Türkçesinde bazı örneklerde derin yapının öznesinin yüzey yapıda kullanıldı̆̆ı hâlde edilgenliğin ifade edilmesinde de kullanıldığ görülmektedir. Bu kullanımlarda derin yapıdaki eylem, yüzey yapıda sıfat fiil ile bir tamlama oluştururken hâl ekleri kullanılmamıştır. Bu nedenle bu cümle "babası tarafından yazılan kitabı" şeklinde Türkiye Türkçesine aktarıldığı gibi “babasının yazdığı kitabı" şeklinde de aktarılabilir. Burada -gan sıfat fiil ekinin bir özelliği de ortaya çıkmaktadır. Özbek Türkçesinde -gan sıfat fiil eki genellikle üzerine bir tamlama eki kabul etmemektedir. Bu nedenle derin yapıdaki eylem yüzey yapıya taşındığında etken mi edilgen mi olduğu net olarak anlaşılamamaktadır. Cümle Türkiye Türkçesine aktarılırken edilgenliğin ifade edilebilmesi için ya -DIk sıfat fiil ekinin pasiflik ifadesinden faydalanılmakta ya da tarafından edatıyla edilgenlik pekiştirilmektedir.

Borar yerdan kechikma, bormas yerga ichikma "Gidilen yere gecikme, gidilmeyen yere girme"

Ba'zan esa daf'atan qaraganda bir-biri bilan moslashmagan va hatto bir-birini birmuncha inkor etuvchi fikrlar ham izhor etilib kelinmoqda (Doniyorov vd., 1976, s. 75) "Bazen ise aniden bakıldığında birbiriyle uymayan ve hatta birbirini çoğu zaman inkâr eden fikirler de ifade edilmektedir."

Shunday qilib, ma'lum bir fikrni bildirgan so'zlar birikmasi gapni tashkil qiladi (Yoqubov vd., 1975, s. 4). "Bu nedenle, belirli bir fikrin ifade edildiği kelimeler topluluğu cümleyi oluşturur."

Harakatning shu so'z bildirgan son-mikdorda bajarilganini bildiradi (Yoqubov vd., 1975, s. 4). “Eylemin bu kelime ile belirtilen miktarda/belirtildiği kadarıla gerçekleştirildiğini gösterir." 
Özbek Türkçesinde -(i)l ve -(i)n edilgen biçimbirim olarak kullanılmaktadır. Etken çatıdaki bir fiil, edilgen yapılmak istendiğinde diğer Türk lehçelerinde olduğu gibi bu biçimbirimler yardımıla yapılmaktadır. Yani genel olarak Türk dilinin edilgenlik kategorisi, Özbek Türkçesinde de işletilmektedir. Yukarıdaki örneklerde görüldüğü gibi edilgen biçimbirimsiz de edilgenlik ifade edilmektedir. Bu durum Türk dilinin tarihî dönemlerdeki edilgen yapıyı henüz tam olarak kullanma olgunluğunda olmadığı eskicil yapıların izi olabilir. Bununla birlikte Türk dilinde edilgen biçimbirimlerin derin yapıdaki öznenin yüzeye taşınmasına izin vermemesi de olabilir. Burada Yönetim ve Bağlama Kuramı özellikleri dikkate alınmalıdır. Türk dilinde derin yapıdaki cümlelerin yüzeye taşınmasında sıfat fiilli yapılar etkin rol almaktadır. Dolayısıyla Özbek Türkçesinde incelenen bu örneklerde ve hem tarih î hem de diğer çağdaş Türk lehçelerinde biçimbirimsiz edilgen yapıların oluşumunda sıfat fiil ekleri sıklıkla karşımıza çıkmaktadır. Çünkü birleşik fiil yapılarında derin yapıdaki iki ayrı cümlenin yüzeyde birleşmesinde sıfat fiil ekleri bağlayıcı rolünü üstlenmektedir. Özbek Türkçesinde derin yapıdaki özne yüzeye kısa bir sürede taşındığ ancak edilgen biçimbirimleri almamıştır. Çünkü yüzeyde derin yapının öznesinin izi olabilmesi için biçimbirimsiz olmak zorundadır. İşte Özbek Türkçesinde biçimbirimsiz edilgen yapıları oluşumu genel olarak bu şekilde teşekkül etmektedir.

\section{Sonuç}

Sonuç olarak tarihî Türk lehçelerinden çağdaş Türk lehçelerine kadar biçimbirimsiz edilgen yapıların oluşumunda $-l$ ve $-n$ biçimbirimlerinin kullanılmıştır. Bugün Özbek Türkçesinde de yine bu biçimbirimler edilgen yapıların oluşumunda kullanılmaktadır. Aynı zamanda dönüşlü çatıdaki fiillerin oluşumunda aynı biçimbirimlerin kullanılıyor olması bazen karışıklığa sebep olmaktadır. Böyle durumlarda fiil semantik açıdan incelenmeli ve cümlenin anlamına bakılmalıdır. Yapılan incelemelerde Özbek Türkçesinde edilgen yapıların birleşik cümlenin yan cümlesi olması durumunda -gan sıfat fiil ekiyle birlikte edilgen yapının ana cümleye bağlandığı tespit edilmiştir. Özbek Türkçesinde ayrıca biçimbirimsiz edilgen ifadeler kullanımı da bir hayli yaygındır. Özbek Türkçesinde biçimbirimsiz edilgen yapılarda -gan sıfat fiil eki daha sık kullanılmıştır. Bu sıklıkta Çağatay Türkçesinde - gan sıfat fiil ekinin -mış ve -DIk ekinin de yerini almaya başlamış olması ve zamanla kullanım alanının genişlemiş olması etkili olmuştur. Özellikle -DIk sıfat fiil ekinin pasiflik ifadesini -gan sıfat fiil ekinin üstlenmiş olması edilgen yapılarda -gan ekinin kullanım sıklığını arttırmıştır. Tabii ki Özbek Türkçesinin, günümüzde Çağatay Türkçesinin devamı niteliğinde olması da bunda etkili olmuştur. Yine Özbek Türkçesinde edilgen biçimbirimsiz yapılarda sıfat fiil ekinin kullanılması da bir diğer dikkat çekici özelliktir. Çünkü derin yapıdaki cümlenin yüzeye taşınmasında sıfat fiil ekleri büyük bir kolaylık sağlamaktadır. Türk dilinin geneline bakıldığında bu durum daha iyi anlaşılmaktadır. Yüzeydeki birleşik yapılarda sıfat fiil ekleri bağlama görevini üstlenmiştir. Derin yapıdaki etken fiilin yüzeye taşınabilmesi edilgen biçimbirimsiz olmalıdır. Çünkü Türk dilinde edilgenlik biçimbirimler bu taşınmaya izin vermemektedir. Bu taşınma sırasında ilk taşınan öge özne olduğu kabul edilirse taşınan fiil de etken biçimbirimde olmak zorundadır. 


\section{Kisaltmalar}

$\begin{array}{ll}\text { AH } & \text { Atabetü'l-Hakayık } \\ \text { DLT } & \text { Dîvânu Lugati't-Türk } \\ \text { ETŞ } & \text { Eski Türk Şiiri } \\ \text { KE } & \text { Kisasü'l-Enbiya } \\ \text { KK } & \text { Kecha va Kunduz } \\ \text { UX } & \text { Ulug'bek Xazinasi }\end{array}$

\section{Kaynakça}

Arat, R. R. (2006). Edib Ahmed b. Mahmud Yüknekî, Atebetü'l-Hakāyık. Ankara: TDK Yayınları. Arat, R.R. (1991). Kutadgu Bilig: I Metin. Ankara: TDK Yayınları.

Ata, A. (2019). Rabg்uzi Kısasü'l-Enbiyā (Peygamber Kıssaları) Giriş-Merin-Dizin. Ankara: TDK Yayınları.

Atay, A. (2019). “Türkçede Eksiz Edilgenlik (Pasiflik) İfadesi”. Avrasya Uluslararası Araştırmalar Dergisi, 7, s. 456-465.

Baasanjav, T. (2006). Türkiye Türkçesi ile Halha Moğolcasında Çatı. (Doktora tezi, Ankara Üniversitesi, Ankara). Erişim adresi: http://tez2.yok.gov.tr/

Banguoğlu, T. (2008). Türkçenin Grameri. Ankara: TDK Yayınları.

Buran, A., Alkaya, E. (2013). Çă̆daş Türk Lehçeleri. Ankara: Akçă̆ Yayınları.

Cho'lpon (1993). Kecha va Kunduz. Toshkent: G'afur G'ulom nomidagi adabiyot ve san'at nashriyoti.

Doniyorov, X., (1976). Eski O'zbek Adabiy Tili va Qipchoq Dialektlari. Toshkent: O’zbekiston Respublikasi Xalq Ta'limi Vazigir Ajınıyoz Nomidagi Nukus Davlat Pedagogiika Instituti.

Duru, M. Ö. (2008). Türk Dilinde Edilgen Çatı. (Yüksek lisans tezi, Ondokuz Mayıs Üniversitesi, Samsun). Erişim adresi: http://tez2.yok.gov.tr/

Eckmann, J: (2003). Çağatayca El Kitabı. Çev. Günay Karaağaç, Ankara: Akçağ Yayınları.

Elbek (1999). Tanlangan Asarlar. Ishq Savdosi. Toshkent: Sharq Nashriyot-Matbaa Kontserni Bosh Nashriyoti.

Eraslan, K. (1999). “Türkçede İsim-Fiiller", Türk Gramerinin Sorunlart-II, Ankara: TDK Yayınları.

Eraslan, K. (2012). Eski Uygur Türkçesi Grameri. Ankara: TDK Yayınları.

Ercilasun, A. B. (2005). Örneklerle Bugünkü Türk Alfabeleri. Ankara: Akçağ Yayınları.

Ercilasun, A. B., Akkoyunlu, Z. (2015). Kâşgarlı Mahmud Dîvânu Lugâti't-Türk Giriş-MetinÇeviri-Notlar-Dizin. Ankara: TDK Yayınları.

Erdem, M. (2007). Historical development of passives in Turkish. L. Karoly (Ed.), Turcology in Turkey Selected papers. (s. 199-210). Macaristan: Szeged. 
F1trat (1993). Fitna San'ati “Tilimiz". Haz. H. Boltaboyev, Toshkent: Fan Nashriyoti.

Gürsoy-Naskali, E. (1997). Türk Dünyası Gramer Terimleri Kılavuzu. Ankara: TDK Yayınları.

Hamroyev, M.A. (2008). Ona Tili. Toshkent: Sharq Nashriyoti.

Jamolxonov, H. (2005). Hozirgi O'zbek Adabiy Tili. Toshkent: Talqin Nashriyoti.

Kambarova, S. (2015). Maktubatlarda Shaxsiyat Tarbiyasi. Til va Adabiyot Ta'limi, O'zbekiston Respublikasi Xalq Ta'limi Vazirligining Ilmiy-Metodik Jurnali, 1, s. 42-44.

Kara, M. (2011). Türkmen Türkçesi Grameri. Ankara: Akçağ Yayınları.

Karadeniz, Y: (2019). Özbek Türkçesinde ve Yeni Uygur Türkçesinde Sifat Fiilli Yapılar: Karşılaştırmalı Dilbilimsel Bir Analiz. (Doktora tezi, Manisa Celal Bayar Üniversitesi, Manisa). Erişim adresi: http://tez2.yok.gov.tr/

Karabulut, F. (2010). “Türk Dilinde Edilgen Biçimbirimsiz Etken Yapı Tipolojisi” Turkish Studies, 5/4, s. 359-400.

Karabulut, F. (2011). Türk Dilinde ve Dünya Dillerinde Edilgen Yapı Tipolojisi Dilbilimsel Bir Inceleme. Ankara: Grafiker Yayınları.

Korkmaz, Z. (2017). Gramer Terimleri Sözlüğü. Ankara: TDK Yayınları.

Kornfilt, J. (1991). A Case for Emerging Funtional Categories", Syntax and Semantic Perspectives on Phrase Structure: Heads and Licensing. San Diego-New York: Academic Press.

Orkun, H. N. (1987) Eski Türk Yazıtları. Ankara: TDK Yayınları.

Öner, M. (2013). “Nominatif hem nul morfema - Nominatif ve Sıfır Morfem”, Soxranenie i razvitie rodnıx yazıkov v usloviyax mongonatsional "nogo gosudarstva: Problemı i perspektivı (V. Mejdunarodnaya nauçno-praktiçeskaya konferantsiya), Kazan: Kazan Federal Üniversitesi, s. 160-162.

Öztürk, R. (2005). Özbek Türkçesi El Kitabı. Konya: Çizgi Kitabevi.

Pinker, S. (1995). The Language Instinct: How to Creats Mind Language. New Yor: Harper Perrnial.

Qahhor, A. (1988). Oltin Yulduz (Qissa). Toshkent: G'afur G'ulom nomidagi adabiyot ve san'at nashriyoti.

Qodiriy, A. (2016). O’tgan Kunlar. Toshkent: Yangi asr avlodi.

Qodirov, P. (1969). Erk (Qissa). Erişim adresi: www.ziyouz.com kutubxonasi

To'xliyev, B., Shamsiyeva, M., Ziyodova, T. (2006). O'zbek Tili O'qitish Metodikasi. Toshkent: O’zbekiston Yozuvchilar Uyushmasi Nashriyoti.

Turgunbayev, C. (2004). Kırgız Türkçesinde Sıfat-Fiil Ekleri. Ankara: TDK Yayınları.

Tursunov, U., Muxtorov, C., Rahmatullayev, Ş. (1975). Hozirgi O'zbek Adabiy Tili. Toshkent: O'qituvchi Nashriyoti.

Üstünova, K. (2007). “Yalın Durum Karmaşası” Turkish Studies, II/4, s. 736-748.

Yazıcı Ersoy, H. (2007). Başkurt Türkçesi. A. B. Ercilasun (Ed.), Türk Lehçeleri Grameri. (s. 749810). Ankara: Akçağ Yayınları. 
Yıldırım, H. (2012). Özbek Türkçesi (Dilbilgisi-Alıştırmalar-Konuşma-Metinler). Ankara: Gazi Kitabevi.

Yılmaz, E. (2002). Çuvaşça Çok Zamanlı Morfoloji. Ankara: Grafiker Yayınları.

Yoqubov, G. A. Shoabdurahmanov, Sh., Haciyev, A.P. (1975). O'zbek Tili Grammatikasi II Tom Morfologiya. Toshknet: O'zbekistan SSR Fen Nashriyoti.

Yoqubov, O. (1994). Ulug'bek Xazinasi. Toshkent: G'afur G'ulom nomidagi adabiyot ve san'at nashriyoti.

Yoqubov O. (2005). Adolat Manzili. Tanlangan Asarlar 1. Jild. Toshkent: “Sharq" NashriyotMatbaa Aktsiyadorlik Kompaniyasi Bosh Taxririyati. 